\title{
Análise das propostas de revisão do zoneamento bioclimático brasileiro: estudo de caso de Colatina, ES
}

\author{
Analysis of the Brazilian bioclimatic zoning: case study of \\ Colatina, ES
}

\section{Alexandre Cypreste Amorim Joyce Correna Carlo}

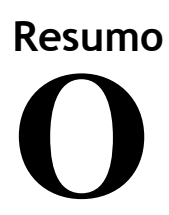

desenvolvimento de zonas bioclimáticas permite a elaboração de estratégias direcionadas para a construção de edifícios que sejam adequados a cada zona particular. No Brasil a NBR 15220-03:2005 apresenta o zoneamento bioclimático brasileiro e as diretrizes construtivas para habitações unifamiliares de interesse social. Porém, desde sua publicação pesquisadores defendem a necessidade de uma revisão no zoneamento referindo, especialmente, a imprecisão na caracterização climática de cidades brasileiras. Por ser a única classificação climática no país, seu uso não se restringe às habitações de interesse social, sendo usada também para outras tipologias, o que reforça a necessidade de revisão. Com a contribuição destes pesquisadores, várias propostas surgiram para a revisão do atual zoneamento. O objetivo é discutir as várias propostas de zoneamento bioclimático brasileiro, tanto a da NBR 15220-3 quanto as propostas de revisão, mediante a aplicação delas à região de Colatina, ES. O método da pesquisa consistiu em aplicar dados dos arquivos climáticos de Colatina a cada uma das metodologias empregadas nas definições de zoneamento bioclimático. As análises mostraram que o método escolhido interfere diretamente na classificação climática de Colatina, fazendo com que a região estudada seja classificada na mesma zona climática, ou em zonas diferentes, das cidades próximas.

Palavras-chaves: Zoneamento bioclimático. Arquivos climáticos. NBR 15220.
Alexandre Cypreste Amoprin Instituto Federal do Espírito Santo Colatina - ES - Brasil

Joyce Correna Carlo Universidade Federal de Viçosa Viçosa - MG - Brasil

Recebido em 24/03/16 Aceito em 12/08/16

\begin{abstract}
The development of bioclimatic zones enables the design of strategies targeted specifically at the different areas where buildings are going to be constructed. The Brazilian Standard NBR 15220-03/2005 features the Brazilian Bioclimatic Zoning and Construction Guidelines For Low-Income Family Housing. However, since its publication, researchers have argued that the Brazilian Bioclimatic Zoning needs to be updated, especially regarding the climate accuracy of Brazilian cities. As this standard is the only climate classification in the country, its recommendations are applied to a wide variety of buildings, which highlights the need for a review. With the contribution of these researchers, several suggestions of updates to the current zoning have emerged. The purpose of this paper is to discuss different proposals for Brazilian bioclimatic zoning, both that of NBR 15220-3's and its review proposals, through their application in the region of Colatina, in the sate of Espirito Santo. The research method consisted in applying the Colatina climate database files to each methodology employed in the definitions of bioclimatic zoning. The results showed that the chosen method directly interferes in the climate classification of Colatina: depending on the method used, the area under study may be considered to be in the same zone as its neighbouring cities or in a different one.
\end{abstract}

Keywords:. Bioclimatic zoning. Weather Data. NBR 15220.

AMORIM, A. C.; CARLO, J. C. Análise das propostas de revisão do zoneamento bioclimático brasileiro: estudo de caso 


\section{Introdução}

Para Rocha, Assis e Gonçalves (2009), o desenvolvimento de zonas bioclimáticas permite a elaboração de estratégias direcionadas para a construção de edifícios que sejam adequados a cada zona particular, e nesse contexto existem várias normas que tratam do assunto. No âmbito mundial, pode-se citar o International Energy Conservation Code (IECC) (INTERNATIONAL..., 2012), existente desde 1998, que é um código norte-americano de eficiência energética para edificações climatizadas artificialmente relacionado ao desempenho térmico das edificações. O IECC fornece diretrizes construtivas para a envoltória das edificações de acordo com um zoneamento climático. Outro exemplo internacional é o código português denominado Regulamento das Características de Comportamento Térmico dos Edifícios (RCCTE) (PORTUGAL, 2006), que classifica Portugal com nove zonas climáticas, para as quais as estratégias bioclimáticas para verão e inverno foram estipuladas com a aplicação do Diagrama Bioclimático de Givoni (ROCHA; ASSIS; GONÇALVES, 2009).

É necessário que arquitetos e urbanistas conheçam as características climáticas do local onde a obra será construída, e um mapeamento sistemático das estratégias bioclimáticas permite melhor compreensão e aplicação de práticas mais comprometidas com a qualidade ambiental dos projetos (MARTINS; BITTENCOURT; KRAUSE, 2012). Estudos que tratam de zoneamento bioclimático mostram-se como importante elemento de melhoria para o entendimento dos climas locais e, consequentemente, para o ato de projetar de forma adequada. Porém, até o fim do século passado a cobertura do território brasileiro por estações meteorológicas era pouca, fazendo com que existissem várias lacunas referentes a medições de dados climáticos satisfatórios na área de arquitetura e engenharia.

O território brasileiro é extenso e possui uma larga diversidade climática com particularidades para cada região, o que demonstra a necessidade de identificação dessas características e, consequentemente, do agrupamento de suas principais zonas bioclimáticas, para se formularem diretrizes construtivas para cada uma dessas zonas. Porém, ainda se encontram alguns limitadores para a construção de um mapeamento que seja mais preciso e completo. Uma dessas limitações mais significativas encontradas na definição do zoneamento bioclimático brasileiro foi a ausência de séries históricas completas de dados climáticos, e também um número reduzido de estudos sobre esse tema em várias localidades brasileiras (MARTINS; BITTENCOURT; KRAUSE, 2011). Nesse contexto, Roriz (1999) cita que menos de 4\% dos mais de 5.500 municípios brasileiros possuíam dados climáticos publicados. Pezzopane et al. (2012) afirmam que a caracterização dos elementos relativos ao clima ainda é feita de modo pontual em algumas estações meteorológicas. Isso cria uma situação em que o conhecimento do clima e de sua variabilidade no território só é possível a partir de procedimentos de interpolação espacial de dados climáticos. A interpolação dos dados constitui-se de uma ferramenta necessária quando há a necessidade de se estimar uma variável qualquer em determinado ponto onde não foi realizada a medição. Sendo assim, é necessário que na região de interesse existam pontos amostrais em suas proximidades onde a variável estudada foi medida, de forma a permitir estimar a variável para o local de interesse utilizando-se funções matemáticas específicas (PEZZOPANE et al., 2012).

Segundo a NBR 15220-3 (ABNT, 2005), o território brasileiro foi dividido em 6.500 células, cada uma caracterizada por sua posição geográfica e pelas variáveis climáticas de médias mensais das temperaturas máximas, médias mensais das temperaturas mínimas e médias mensais das umidades relativas do ar. Porém, para apenas 330 dessas células contou-se com dados das normais climatológicas medidos entre 1930 e 1990 (ABNT, 2005). Para as demais regiões os climas foram estimados pelo método de interpolação, e Colatina foi um dos municípios brasileiros que teve seus dados obtidos por esse último método.

Desde 2012 algumas propostas de revisão da NBR 15220-3 (ABNT, 2005) referentes à parte de classificação dos climas no Brasil foram disponibilizadas no site do Laboratório de Eficiência Energética em Edificações (LabEEE) da Universidade de Santa Catarina, para que pesquisadores pudessem contribuir com este trabalho. Essa revisão foi decorrente de inúmeras críticas apresentadas ao zoneamento desde sua publicação, em 2005. Roriz (2012a) ressalta que as críticas realizadas são justificadas, pois se referem à imprecisão na caracterização climática de cidades brasileiras. Da publicação do zoneamento, em 2005, até as atuais propostas de revisão o número de estações meteorológicas capazes de fornecer dados confiáveis aumentou de 330 para 1.513 locais com dados climáticos disponíveis, reduzindo o número de localidades cuja zona 
bioclimática é definida por métodos de interpolação (RORIZ, 2012a).

Segundo a ABNT (2005), para a confecção do zoneamento bioclimático brasileiro das 330 localidades, foram utilizados dados das normais climatológicas medidos de 1961 a 1990 em 206 cidades e dados das normais climatológicas e outras fontes medidos de 1931 a 1960 em 124 cidades. Já Roriz (2012a) afirma que para a primeira proposta de revisão 400 municípios tiveram seus dados obtidos de anos típicos calculados sobre dados horários históricos no período de 2000 a 2010 das estações automáticas do Inmet, enquanto em 22 municípios os dados foram obtidos de dados diários históricos no período de 2000 a 2010 de estações convencionais do Inmet, e 188 municípios através das normais climatológicas de 1961 a 1990. Segundo Carvalho, Araújo e Silva (2002, p. 328), a criação de um arquivo TRY,

\section{[...] consiste de um ano típico representativo de determinado lugar geográfico considerando-se um período mínimo de 10 anos consecutivos de séries de dados climáticos [...].}

Porém Goulart (2010 ${ }^{1}$ apud TAVARES; AMORIM, 2011) ressalta que "[...] é importante dar preferência para uma série de anos mais atuais, mesmo que seja uma série menor que 10 anos [...]". Dessa forma, considerando o número maior de dados obtidos por estações automáticas do Inmet, alguns arquivos foram gerados com períodos menores do que os 30 anos das normais climatológicas utilizadas para o zoneamento bioclimático brasileiro da NBR 15220-3 (ABNT, 2005).

O conhecimento específico do clima na região de Colatina, com base nos dados climáticos obtidos em uma estação meteorológica do Instituto Capixaba de Pesquisa, Assistência Técnica e Extensão Rural (Incaper), possibilita analisar a região estudada, seja no contexto do atual zoneamento bioclimático brasileiro, seja pelas propostas de revisão que se encontram em desenvolvimento. Dessa forma, esta pesquisa teve como objetivo discutir as várias propostas de zoneamento bioclimático brasileiro, tanto a presente na NBR 15220-3 quanto nas propostas de revisão, ao aplicá-las à região de Colatina, ES.

\section{Zoneamento bioclimático brasileiro}

\section{Zoneamento publicado na NBR $15220 / 2005$}

O zoneamento bioclimático brasileiro surgiu de um trabalho iniciado em 1988 pelo Grupo de Conforto Ambiental e Eficiência Energética, da Associação Nacional da Tecnologia do Ambiente Construído (ANTAC). Desde essa época, o Grupo vinha trabalhando para iniciar um processo brasileiro para normalização sobre o tema de requisitos mínimos aceitáveis de desempenho térmico para habitações de interesse social. Na década de 1990 Silva (1994) propôs um zoneamento bioclimático brasileiro para fins de edificação, utilizando as normais climatológicas de 204 cidades brasileiras, e propôs 13 zonas bioclimáticas, obtidas através do cruzamento de estratégias bioclimáticas de resfriamento e de aquecimento.

Segundo Roriz, Ghisi e Lamberts (1999), em 1991 realizou-se o Primeiro Encontro Nacional Sobre Normalização Quanto ao Uso Racional de Energia e ao Conforto Térmico em Edificações, e muitos passos foram dados para o estabelecimento das normas brasileiras no âmbito do desempenho térmico. Dessa forma, buscando-se unificar e oficializar o processo, foi criada a Comissão de Estudos sobre Desempenho Térmico e Eficiência Energética de Edificações, que estava vinculada ao Comitê Brasileiro de Construção Civil da Associação Brasileira de Norma Técnicas (ABNT). Do trabalho dessa comissão surgiram quatro temas de trabalho, e um deles, o de Procedimentos de Avaliação do Desempenho Térmico de Habitações Populares, foi encarregado de formular um texto que contivesse apenas diretrizes construtivas para a otimização do desempenho térmico de habitações de interesse social (RORIZ; GHISI; LAMBERTS, 1999).

Em 2005 esse item foi aprovado como parte integrante da NBR 15220, estando presente na norma como Desempenho térmico de edificações Parte 3: Zoneamento Bioclimático Brasileiro e diretrizes construtivas para habitações unifamiliares de interesse social (ABNT, 2005). Para a definição desse zoneamento dividiu-se o território brasileiro em oito zonas bioclimáticas, classificadas como relativamente homogêneas quanto ao clima, e " [...] formulou-se um conjunto de recomendações técnico-construtivas que otimizam o desempenho térmico das edificações, através de sua melhor adequação climática [...]" (ABNT, 2005, p. 2).

${ }^{1}$ GOULART, S. Metodologia Para Identificação do TRY. 
A metodologia utilizada para a definição do atual zoneamento baseou-se nos desvios da zona de conforto adaptada do diagrama psicrométrico proposto por Givoni em 1992 (ABNT, 2005). A classificação das cidades brasileiras foi feita com dados das normais climatológicas divulgadas pelo Instituto Nacional de Meteorologia (Inmet) para 330 cidades, e eles foram utilizados também para se estimar, pelo método de interpolação, o clima das demais cidades (MARTINS; BITTENCOURT; KRAUSE, 2012). Porém, segundo a ABNT (2005), para 330 dessas células utilizaram-se os dados das normais climatológicas medidos de 1961 a 1990 em 206 cidades (4\% do total), e dados das normais climatológicas e outras fontes medidos de 1931 a 1960 em 124 cidades (2\% do total), sendo que o país possui 5.561 cidades segundo o IBGE (2013), o que demonstra baixa expressividade dos dados levantados na época. Segundo Roriz (2012a), desde a publicação da NBR 15220, inúmeras críticas ao zoneamento surgiram referentes à imprecisão na caracterização climática de cidades brasileiras. Há também o argumento de que, devido à variação regional, fazse necessário o estudo específico para os índices e zonas de conforto térmico-ambiental. Trabalhos como os de Pereira e Assis (2004), Bogo (2008) e Martins, Bittencourt e Krause (2012) apresentam questionamentos sobre o atual zoneamento bioclimático brasileiro (FERREIRA; SOUZA; ASSIS, 2014).

A NBR 15220-3 (ABNT, 2005) cita apenas cinco cidades classificadas no estado do Espírito Santo em seu texto: Conceição da Barra, Linhares, São Mateus, Vitória e Cachoeiro de Itapemirim. Como o mapa do zoneamento constante da norma não permite análises precisas devido a sua baixa resolução, a confirmação de em qual zona o município de Colatina está inserido foi feita com o auxílio do programa ZBBR - Zoneamento Bioclimático do Brasil (RORIZ, 2004). Pela Figura 1 a zona bioclimática na qual está inserida Colatina é a Zona Bioclimática 8 .

A Tabela 1 mostra os dados referentes às respectivas latitudes, longitudes e altitudes dos principais municípios da região próxima a Colatina comparados Aimorés, MG, com base nos dados do IBGE e da NBR 15220-3.

Vale ressaltar que Vitória, Linhares e Aimorés têm normais climatológicas, que foram as bases para a determinação do zoneamento bioclimático, enquanto Colatina não tem tais dados. Como a zona bioclimática de Colatina foi determinada pelo método de interpolação linear com as cidades próximas, surgem os questionamentos de sua ideal inserção no atual zoneamento, considerando sua proximidade com Aimorés, MG, classificada como ZB5.

Figura 1 - Informações sobre Colatina segundo a classificação o programa ZBBR

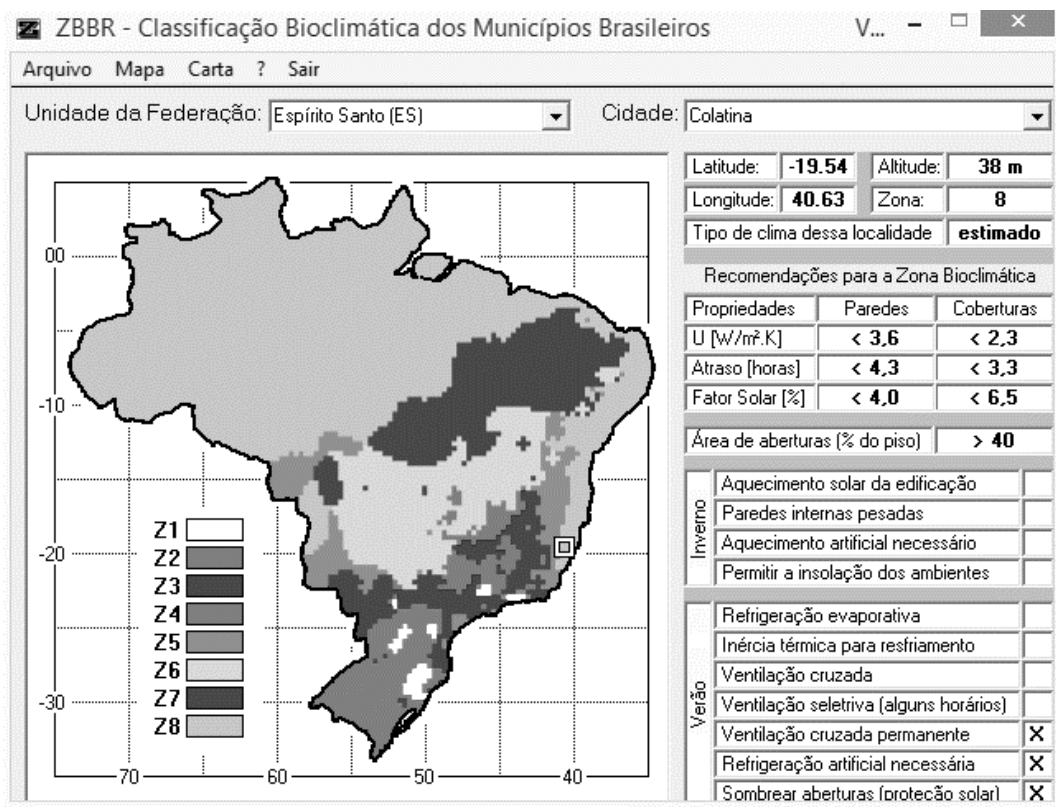

Fonte: Roriz (2004). 
Tabela 1 - Dados dos municípios

\begin{tabular}{c|c|c|c|c|c|c}
\hline UF & Município & Latitude & Longitude & $\begin{array}{c}\text { Altitude } \\
\text { ortométrica } \\
(\mathbf{m})\end{array}$ & $\begin{array}{c}\text { Distância } \\
\text { (km) em } \\
\text { relação a } \\
\text { Colatina }\end{array}$ & $\begin{array}{c}\text { Zona } \\
\text { bioclimática } \\
\text { pela NBR } \\
\mathbf{1 5 2 2 0 - 3}\end{array}$ \\
\hline ES & Baixo Guandu & $1^{\circ} 29^{\circ} \cdot \mathrm{S}$ & $4^{\circ} 01^{\circ} 02^{\prime} \mathrm{W}$ & 72,75 & 40,10 & 8 \\
$\mathrm{ES}$ & Colatina & $1^{\circ} 29^{\prime} \mathrm{S}$ & $40^{\circ} 45^{\prime} \mathrm{W}$ & 68,90 & 0 & 8 \\
$\mathrm{ES}$ & Marilândia & $1^{\circ} 24^{\prime} \mathrm{S}$ & $40^{\circ} 32^{\prime} \mathrm{W}$ & 92,28 & 16,50 & 8 \\
$\mathrm{ES}$ & Linhares & $1^{\circ} 34^{\circ} \mathrm{S}$ & $39^{\circ} 57^{\prime \prime \prime} \mathrm{W}$ & 9,41 & 61,95 & 8 \\
$\mathrm{ES}$ & Vitoria & $2^{\circ} 18^{\prime} \mathrm{S}$ & $40^{\circ} 19^{\prime} \mathrm{W}$ & 21,53 & 91,55 & 8 \\
$\mathrm{MG}$ & Aimorés & $1^{\circ} 29^{\circ} \mathrm{S}$ & $41^{\circ} 05^{\prime} \mathrm{W}$ & 82,47 & 46,20 & 5 \\
\hline
\end{tabular}

Fonte: IBGE (2013), Google Earth (2015) e ABNT (2005).

\section{Propostas de zoneamento: revisão 2010/2014}

Apesar das considerações e questionamentos feitos sobre a adequação do zoneamento vigente, a NBR 15220-3 (ABNT, 2005) vem cumprindo um papel importante nos indicativos de melhoria do desempenho térmico das habitações de interesse social no país. Porém, passados mais de 10 anos desde sua publicação, algumas considerações já foram feitas com discussões sobre a necessidade de uma revisão desse zoneamento, sendo a primeira proposta de revisão do ano de 2012.

Roriz (2012a) cita que o atual zoneamento foi elaborado com o objetivo específico de atender às habitações unifamiliares de interesse social, porém, por ser durante anos o único material disponível nas normas técnicas brasileiras, é aplicado para qualquer tipo de edificação sem distinções, o que muitas vezes acarreta análises equivocadas sobre a adequação climática das edificações. Não obstante, o zoneamento é adotado por outras normas e regulamentos, posteriores à NBR 15520-3, que tratam de outras tipologias construtivas. São exemplos a NBR 15575 Desempenho de edificações habitacionais e os Regulamentos Técnicos sobre Eficiência Energética (RTQ-C e RTQ-R) do Inmetro.

Com base nessas questões há um consenso entre vários pesquisadores brasileiros que atuam nessa área específica de que existe a necessidade de se fazer uma revisão do zoneamento. Recentemente Ferreira, Souza e Assis (2014) desenvolveram estudos comparando o zoneamento bioclimático brasileiro e a classificação climática proposta por Nimer (1979). Neste trabalho constatou-se que na comparação dos mapas das duas classificações climáticas houve pouca correspondência entre elas. Enquanto Nimer (1979) aborda vários conceitos da climatologia dinâmica, tais como as diferenças que existem nos extremos de temperaturas e a duração destas, e também as distribuiçõos de chuvas e duração de climas secos, o zoneamento bioclimático brasileiro considerou apenas os dados mensais de temperatura média e umidade relativa.

Ao longo desses anos, e com a contribuição de vários pesquisadores no Brasil, várias propostas surgiram para a revisão do atual zoneamento bioclimático brasileiro. Ao contrário do existente na NBR 15220-3, as propostas de revisão do zoneamento bioclimático brasileiro limitam-se à divisão do território brasileiro em zonas com algum nível de homogeneidade climática, sem abordar as recomendações construtivas específicas para cada zona, como consta na NBR 15220-3, deixando para estudos futuros a definição das recomendações construtivas específicas para cada zona (RORIZ, 2012a).

Até o momento já foram feitas cinco propostas de revisão (a proposta denominada versão 2.1 foi desconsiderada neste trabalho porque foi substituída logo depois pela versão 3.0), cada uma tendo nomenclatura própria. Para facilitar a leitura neste artigo e se padronizarem as informações, o Quadro 1 apresenta uma equivalência de nomenclatura entre propostas de revisão do zoneamento bioclimático brasileiro existentes no LabEEE e nesta pesquisa.

Segundo Roriz (2012a), na Proposta 1, de janeiro de 2012, a base de dados climáticos disponíveis foi dividida em três grupos. O Grupo 1 contém dados de média mensal da temperatura mínima do ar (Tmin) e média mensal da temperatura máxima do ar (Tmax), ambas temperaturas de bulbo seco medidas pelo Inmet, e abrange 610 municípios com dados medidos, o que corresponde a $11 \%$ dos municípios brasileiros. O Grupo 2, cujos valores de temperaturas mínimas e médias foram obtidos por regressão linear múltipla, possui 4.954 municípios, cujas temperaturas mínimas e médias foram estimadas por meio de regressões. Tendo essas temperaturas como base, suas respectivas amplitudes foram calculadas. E, por fim, definiu-se o Grupo 3, cujos valores foram obtidos por interpolação dos pontos no país situados fora das 
sedes municipais, devido à falta de dados confiáveis de altitudes. Dessa forma, foram obtidos por interpolação os dados de temperaturas médias e mínimas de todos esses pontos. O território brasileiro foi dividido em 233.455 células quadradas, cada uma tendo aproximadamente $6 \mathrm{~km}$ de lado, e as interpolações foram desenvolvidas por meio do programa Surfer-9 (RORIZ, 2012a). A Tabela 2 mostra as fontes dos dados adotados para a primeira proposta de revisão.

\section{Quadro 1 - Equivalência de nomenclatura entre propostas de revisão do zoneamento bioclimático brasileiro do LabEEE e nesta pesquisa}

\begin{tabular}{|l|c|c|}
\hline \multicolumn{1}{|c|}{ Nomenclatura LabEEE } & $\begin{array}{c}\text { Data de } \\
\text { lançamento }\end{array}$ & $\begin{array}{c}\text { Nomenclatura adotada } \\
\text { nesta pesquisa }\end{array}$ \\
\hline $\begin{array}{l}\text { Uma proposta de revisão do zoneamento } \\
\text { bioclimático brasileiro }\end{array}$ & $\mathrm{Jan} / 2012$ & Proposta 1 \\
\hline $\begin{array}{l}\text { Segunda proposta de revisão do zoneamento } \\
\text { bioclimático do Brasil }\end{array}$ & $\mathrm{Ago} / 2012$ & Proposta 2 \\
\hline Classificação de climas do Brasil - versão 2 & Nov/2013 & Proposta 3 \\
\hline Classificação de climas do Brasil - versão 3 & Mar/2014 & Proposta 4 \\
\hline
\end{tabular}

Tabela 2 - Fontes dos dados adotados para a Proposta 1 de revisão

\begin{tabular}{|c|c|l|}
\hline Grupo & $\begin{array}{c}\text { Número de } \\
\text { locais }\end{array}$ & \multicolumn{1}{c|}{ Fonte dos dados } \\
\hline 1 & 400 & $\begin{array}{l}\text { Dados horários históricos no período de 2000 a 2010 das estações } \\
\text { automáticas do Inmet }\end{array}$ \\
\hline 1 & 22 & $\begin{array}{l}\text { Dados horários históricos no período de 2000 a 2010 das estações } \\
\text { convencionais do Inmet }\end{array}$ \\
\hline 1 & 188 & Normais climatológicas - período de 1961 a 1990 \\
\hline 2 & 4.954 & Temperaturas mínimas e médias estimadas por meio de regressões \\
\hline 3 & - & $\begin{array}{l}\text { 233.455 células quadradas de 6 km de lado com dados interpolados no } \\
\text { programa Surfer-9 }\end{array}$ \\
\hline
\end{tabular}

Fonte: Roriz (2012a).

Observa-se que, por essa proposta de revisão, há ainda um número restrito de cidades com dados obtidos através das medições do Inmet (o Grupo 1 corresponde a apenas $11 \%$ dos municípios brasileiros). Barnaby e Crawley (2011) citam que, historicamente, os dados climáticos em larga escala apoiavam as variadas atividades ligadas à aviação e agricultura e que seu uso em aplicações ligadas à área de arquitetura ou engenharia tem recebido atenção apenas mais recentemente. De fato, mesmo ocorrendo aumento do número de estações, a primeira proposta do novo zoneamento ainda conta com pouco mais de $10 \%$ do território nacional com dados registrados por estações meteorológicas. Após a divulgação da Proposta 1 várias críticas e sugestões foram feitas por pesquisadores, identificando-se aspectos que poderiam ser aperfeiçoados, assim como caminhos que poderiam ser percorridos para melhorar a qualidade do trabalho.

A Proposta 2, de agosto de 2012, surgiu como opção para substituir a anterior e foi submetida à apreciação do Grupo de Discussão instituído no âmbito da Antac para rever o zoneamento bioclimático brasileiro. Nesta proposta, os dados de 11 fontes, monitorados em 1.265 lugares do território nacional, foram compilados (RORIZ, 2012b). Mesmo que alguns desses lugares não constituam sedes de municípios, seus dados contribuem para detalhar o mapa climático do país (RORIZ, 2012b). Ainda segundo Roriz (2012b), as principais diferenças entre as duas propostas estão no aumento do número de pontos com dados coletados e a forma de se estimarem as temperaturas para os pontos que não tiveram seus dados medidos. Para esses pontos, estabeleceu-se uma grade com pontos para cada grau de latitude $\mathrm{e}$ longitude, adotando-se para os pontos as médias mensais de Tmax e Tmin medidas por meio de satélites da Nasa (Roriz, 2012b). O Quadro 2 apresenta as principais diferenças definidas por Roriz (2012b), no qual se percebe a duplicação do número de pontos com coleta de dados. 
Quadro 2 - Principais diferenças entre as Propostas 1 e 2 estabelecidas por Roriz (2012b)

\begin{tabular}{|l|l|l|}
\hline \multicolumn{1}{|c|}{ Aspecto } & \multicolumn{1}{c|}{ Proposta 1 } & \multicolumn{1}{c|}{ Proposta 2 } \\
\hline $\begin{array}{l}\text { Número de pontos com dados } \\
\text { medidos }\end{array}$ & 610 & 1.281 \\
\hline $\begin{array}{l}\text { Estimativas de temperaturas em } \\
\text { pontos sem dados medidos }\end{array}$ & $\begin{array}{l}\text { a) Equações de regressão } \\
\text { para sedes de municípios } \\
\text { b) Interpolação para os } \\
\text { pontos restantes }\end{array}$ & $\begin{array}{l}\text { a) Dados medidos por satélite a } \\
\text { cada grau de latitude e longitude } \\
\text { b) Interpolação para os pontos } \\
\text { restantes }\end{array}$ \\
\hline $\begin{array}{l}\text { Compatibilização entre dados } \\
\text { medidos em diferentes períodos }\end{array}$ & Não & Sim \\
\hline
\end{tabular}

Fonte: Roriz (2012b).

Segundo Roriz (2012b), na compatibilização dos valores foi desenvolvido um método para identificar as taxas anuais de variação das temperaturas típicas de cada região do país levando-se em consideração o fenômeno atualmente conhecido como "mudanças climáticas globais". Assim, a aplicação dessas taxas permitiu transpor cada conjunto de dados para o ano de 2010, que foi escolhido como referência para a definição do zoneamento.

Em 2013, após várias contribuições de pesquisadores, foi lançada a Proposta 3, que contou com novas fontes de dados, incluindo os de seis localidades no Espírito Santo, com informações de estações do Incaper. Segundo Roriz (2013), o principal objetivo dessa proposta é estabelecer um mapeamento dos climas do Brasil e, posteriormente, através de simulações computacionais, definir zoneamentos bioclimáticos específicos para as diferentes tipologias e, dessa forma, identificar as estratégias construtivas mais recomendadas para cada tipologia. Essa proposta conta com dados medidos em 1.131 lugares do território brasileiro, além de dados obtidos por meio de satélites pela Nasa. Assim, o número de cidades brasileiras aumentou para 1.513, além da inclusão de 230 cidades de outros países sulamericanos, uma vez que estes dados contribuem para o processo de interpolação dos mapas resultantes (RORIZ, 2013).

Já em março de 2014 a Proposta 4 propôs melhorias com relação à proposta anterior, considerando-se que até aquele momento a Proposta 3 dava preferência às médias obtidas com base em períodos históricos mais longos. Por essa razão utilizaram-se 14 arquivos em formato epw da base da Antac na Proposta 3. Porém, segundo Roriz (2014), percebeu-se que os arquivos em formato epw seriam necessários para simulações computacionais contempladas para uma próxima etapa da revisão do zoneamento bioclimático brasileiro, com vistas às recomendações construtivas, sendo assim a quantidade de dados provenientes de estações convencionais do Inmet diminui de 263 (Proposta 3) para 110 (Proposta 4), e houve aumento de dados baseados em arquivos epw da base da Antac, de 14 (Proposta 3) para 413 (Proposta 4).

Para esta proposta, o número de cidades brasileiras soma 1.511, pois duas foram excluídas por estarem repetidas, além da manutenção de 226 cidades de outros países sul-americanos. Com isso, há um esforço contínuo para que a revisão do zoneamento bioclimático brasileiro ocorra, cada vez mais, com um maior número de cidades que representem o clima local através de dados obtidos das mais variadas fontes, fazendo com que o número de 330 cidades do zoneamento em vigor tenha aumentado para mais de 1.500 , o que representa hoje $27 \%$ municípios brasileiros, e não apenas $6 \%$, na criação da NBR 15220.

\section{Métodos de classificação bioclimática}

Esta pesquisa compilou arquivos climáticos TRY e TMY2 para Colatina com dados medidos na estação meteorológica do Incaper, situado em Marilândia, ES (distante 16,5 km do local de estudo), por ser esta a cidade mais próxima de Colatina com uma estação meteorológica automática. Os arquivos climáticos foram utilizados para fazer a análise das propostas de zoneamento bioclimático, verificando a inserção de Colatina tanto na versão do atual zoneamento bioclimático brasileiro, constante da NBR 15220 (ABNT, 2005), quanto nas versões de revisão. Cada uma dessas versões tem uma metodologia própria para classificar os climas. Algumas usam dados de médias das temperaturas máximas e mínimas, outras trabalham com graus hora ou com amplitudes térmicas. Por isso, cada método de análise é explicado a seguir.

\section{Método da NBR 15220}

Segundo Roriz, Ghisi e Lamberts (1999), o atual zoneamento baseou-se em adaptações efetuadas 
sobre a Carta Bioclimática de Givoni (Figura 2), sem o intuito de questionar seus fundamentos teóricos. A carta adaptada pela metodologia proposta por Roriz, Ghisi e Lamberts (1999) para a definição do atual zoneamento dividiu a zona de conforto da carta original em duas subzonas e uma com umidades relativas entre $30 \%$ e $50 \%$, criandose assim a zona $\mathrm{D}$, e outra com umidades entre $50 \%$ e $80 \%$ - zona E (RORIZ; GHISI; LAMBERTS, 1999).

Roriz, Ghisi e Lamberts (1999) explicam que na carta adaptada a estratégia de ventilação sofreu uma divisão em duas zonas ( $\mathrm{J}$ e I), sendo que a zona $\mathrm{J}$ só se aplica quando altas temperaturas se conjugam com altas umidades. Também foi necessária a criação da zona $\mathrm{F}$, em que se recomenda a substituição do ar úmido interior pelo ar exterior mais seco. Esta última zona exige taxas de ventilação mais baixas do que a zona $J$. Utilizando-se essa carta adaptada, procedeu-se à inserção dos dados mensais de temperatura e umidade do ar para cada mês, e se utilizou a temperatura média das mínimas, a temperatura média das máximas e a média mensal da umidade relativa. Pela Figura 3 verifica-se que na interseção entre Tmed e UR marca-se um ponto definido como ponto "a", cuja correspondente à umidade absoluta é considerada como média do mês (Umed). Essa operação é repetida para os 12 meses do ano, obtendo-se, dessa forma, as porcentagens de cada estratégia para o ano.

\section{Método das propostas de revisão do zoneamento bioclimático brasileiro}

Cada proposta de revisão possui métodos próprios de classificação, bem como alterações ou atualizações com relação à base de dados utilizada. Neste trabalho constam as descrições de cada proposta, sem, contudo, se aprofundar na discussão sobre a criação desses métodos empregados em Roriz (2012a, 2012b, 2013, 2014).

A Proposta 1, de janeiro de 2012, constante em Roriz (2012a), trabalha com o aumento do número de zonas bioclimáticas de 8 para 20. A Proposta 2, constante em Roriz (2012b), aumenta o número de zonas de 8 para 16. Posteriormente, em 2013 e 2014, surgiram as Propostas 3 e 4. Estas novas propostas estabelecem um número total de 24 zonas bioclimáticas. Vale ressaltar que a Proposta 3 sofreu algumas alterações e recebeu uma versão com 32 zonas bioclimáticas, mas foi revista, e a versão mais atual (Proposta 4) mantém as 24 zonas. Cada proposta traz algumas particularidades de métodos para a classificação dos climas de cada localidade. As duas primeiras propostas apresentadas em 2012 trabalham com a terminologia apresentada no Quadro 3.

Figura 2 - Carta bioclimática adaptada e suas estratégias de condicionamento

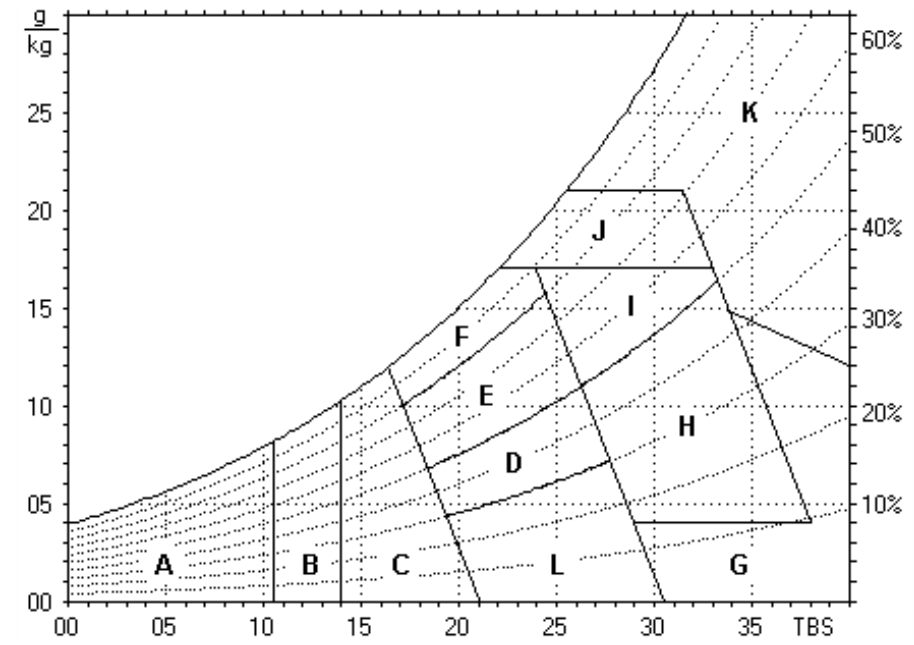

Fonte: Roriz, Ghisi e Lamberts (1999). 
Figura 3 - Representação gráfica do clima

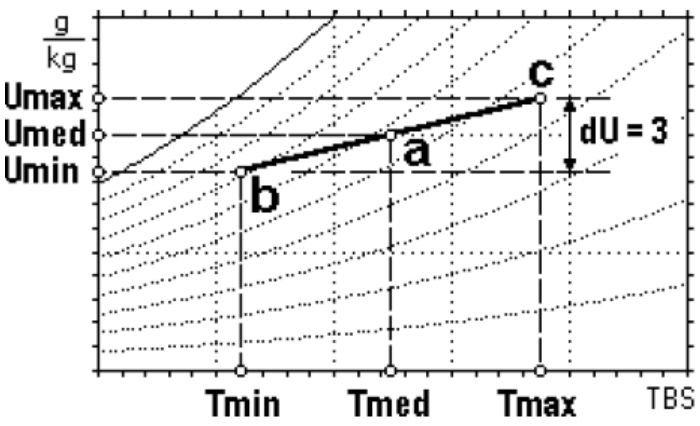

Fonte: Roriz, Ghisi e Lamberts (1999).

Quadro 3 - Terminologia usada por Roriz (2012a) para revisão

\begin{tabular}{|l|l|}
\hline Tmin $(\mathrm{m}):$ média mensal da temperatura mínima do ar & $(\mathrm{m})=$ mês \\
\hline Tmax $(\mathrm{m}):$ média mensal da temperatura máxima do ar & $(\mathrm{m})=$ mês \\
\hline Tmed(m): média mensal da temperatura média do ar & Tmed $(\mathrm{m})=[\operatorname{Tmin}(\mathrm{m})+\operatorname{Tmax}(\mathrm{m})] / 2$ \\
\hline Amed(m): média mensal da amplitude térmica & Amed $(\mathrm{m})=\operatorname{Tmáx}(\mathrm{m})-\operatorname{Tmin}(\mathrm{m})$ \\
\hline Tmed(m): média anual da temperatura do ar & Tmed $=\left[\sum_{m=1}^{12} \operatorname{Tmed}(m)\right] / 12$ \\
\hline Amed(m): média anual da amplitude térmica & Amed $=\left[\sum_{m=1}^{12} A m e d(m)\right] / 12$ \\
\hline
\end{tabular}

Fonte: adaptado de Roriz (2012a).

Segundo Roriz (2012b), existem vários métodos de classificação climática, cada um voltado para diferentes objetivos, sejam destinados a agricultura, biologia ou mesmo geologia. O objetivo principal da Proposta 1 foi estabelecer um método que permita dividir o território brasileiro em um número de zonas que possam refletir da melhor maneira possível a diversidade climática do Brasil no que se refere ao comportamento térmico e energético de edificações. Conforme Roriz (2012b), essa tarefa é extremamente complexa e envolve aspectos polêmicos entre os diversos pesquisadores da área. Adotar critérios que sejam muito rigorosos pode resultar em uma excessiva quantidade de zonas. Por outro lado, critérios que sejam muito genéricos tendem a mascarar diferenças climáticas que podem ser de extrema significância para o comportamento térmico e energético de edificações.

\section{Proposta 1}

Na Proposta 1 do zoneamento, cada um desses parâmetros foi dividido em intervalos, cujos limites foram definidos tomando-se por base as análises dos dados climáticos das 610 estações do denominado Grupo 1. Roriz (2012a) verificou que com pequenas alterações nos limites estabelecidos ocorrem diferenças significativas no que se refere à abrangência das zonas. A Tabela 3 apresenta a primeira proposta de critérios para definição das zonas bioclimáticas no Brasil, com base no cruzamento dos resultados das temperaturas médias anuais com as amplitudes médias anuais.
Os valores de dT são dados pela diferença entre a maior e a menor temperatura média mensal, e de dA pela diferença entre a maior e a menor amplitude térmica mensal.

\section{Proposta 2}

A Proposta 2 aplica dois parâmetros para classificação dos climas: total anual de graus-horas de calor (GhC) e total anual de graus-horas de frio (GhF). Esses parâmetros foram definidos baseados nos intervalos confortáveis de temperatura obtidos na carta bioclimática proposta por Givoni, ou seja, $18^{\circ} \mathrm{C}$ a $28^{\circ} \mathrm{C}$, sendo $18^{\circ} \mathrm{C}$ o limite inferior da zona de conforto e $28{ }^{\circ} \mathrm{C}$ o limite superior para diferentes taxas de umidade (RORIZ, 2012b). Assim como a proposta anterior, há a certeza de que os métodos de classificação climática são muitos e cada um com seu objetivo específico, e que a tarefa é dividir o território brasileiro em zonas que reflitam a diversidade climática do país em relação ao comportamento térmico e energético de edificações da melhor forma possível (RORIZ, 2012b).

Sendo assim, os indicadores foram calculados pelas fórmulas constantes das Equações 1 e 2 .

$\begin{aligned} & \mathrm{GhC}=\sum_{n=1}^{12} \mathrm{Tmax}(\mathrm{m})-28(\text { se a } \operatorname{Tmax}(\mathrm{m})>28 \\ & \left.{ }^{\circ} \mathrm{C}\right) \\ & \text { Eq. } 1\end{aligned}$
$\begin{aligned} & \mathrm{GhF}=\sum_{n=1}^{12} 18-\mathrm{Tmin}(\mathrm{m})(\mathrm{se} \text { a } \operatorname{Tmin}(\mathrm{m})<18 \\ & \left.{ }^{\circ} \mathrm{C}\right) \\ & \text { Eq. } 2\end{aligned}$

Sendo: 
$\operatorname{Tmax}(\mathrm{m}):$ média das temperaturas máximas do mês "m"; e

Tmin(m): média das temperaturas mínimas do mês "m".

Dessa forma, chegou-se a uma nova proposta de zoneamento, com 16 zonas separadas pelos intervalos de $\mathrm{GhC}$ e $\mathrm{GhF}$, conforme apresentado na Tabela 4.

\section{Proposta 3}

A Proposta 3 traz, além de um aumento das fontes de dados climáticos tratados para 1.513, outra metodologia de critérios para classificação dos climas, incluindo o cálculo do desvio padrão da média mensal das temperaturas médias diárias e desvio padrão da amplitude da média mensal, conforme o Quadro 4, com as terminologias utilizadas nesta versão.

Segundo Roriz (2013), essa proposta busca evitar que existam grupos com um número inexpressivo de cidades. Então foi feita uma divisão da base de dados em três grupos de temperatura média anual (TMA), sendo eles classificados com os seguintes intervalos: $\mathrm{TMA} \leq 21 ; 21<\mathrm{TMA}<26$; e $\mathrm{TMA} \geq 26$. A Tabela 5 mostra a proposta de classificação por este método com 24 zonas bioclimáticas.

Tabela 3 - Proposta 1 com critérios para definição das zonas bioclimáticas

\begin{tabular}{|c|c|c|c|c|c|c|c|}
\hline & & & \multicolumn{2}{|c|}{ TmedAno $\leq 20$} & \multicolumn{2}{|c|}{$20<$ TmedAno $\leq 26$} & \multirow{2}{*}{$\begin{array}{l}\text { TmedAno > } \\
26\end{array}$} \\
\hline & & & $\mathrm{dT} \leq 8.4$ & $\mathrm{dT}>8.4$ & $\mathrm{dT} \leq 5.4$ & dT $>5.4$ & \\
\hline & & & A1 & A2 & B1 & B2 & C1 \\
\hline \multirow{2}{*}{ AmedAno $\leq 10$} & $\mathrm{dA} \leq 2.3$ & D1 & Z1: A1D1 & Z5: A2D1 & & & \\
\hline & $\mathrm{dA}>2.3$ & D2 & Z2: A1D2 & Z6: A2D2 & & & \\
\hline \multirow{2}{*}{ AmedAno $>10$} & $\mathrm{dA} \leq 2.3$ & E1 & Z3: A1E1 & Z7: A2E1 & & & \\
\hline & $\mathrm{dA}>2.3$ & E2 & Z4: A1E2 & Z8: A2E2 & & & \\
\hline \multirow{2}{*}{ AmedAno $\leq 10$} & $\mathrm{dA} \leq 3.6$ & D1 & & & Z9: B1D1 & Z13: B2D1 & \\
\hline & $\mathrm{dA}>3.6$ & D2 & & & Z10: B1D2 & Z14: B2D2 & \\
\hline \multirow{2}{*}{ AmedAno > 10} & $\mathrm{dA} \leq 3.6$ & E1 & & & Z11: B1E1 & Z15: B2E1 & \\
\hline & $\mathrm{dA}>3.6$ & E2 & & & Z12: B1E2 & Z16: B2E2 & \\
\hline \multirow{2}{*}{ AmedAno $\leq 10$} & $\mathrm{dA} \leq 4.2$ & D1 & & & & & Z17: C1D1 \\
\hline & $\mathrm{dA}>4.2$ & D2 & & & & & Z18: C1D2 \\
\hline \multirow{2}{*}{ AmedAno > 10} & $\mathrm{dA} \leq 4.2$ & E1 & & & & & Z19: C1E1 \\
\hline & $\mathrm{dA}>4.2$ & E2 & & & & & Z20: C1E2 \\
\hline
\end{tabular}

Fonte: Roriz (2012a).

Tabela 4 - Definição das 16 zonas bioclimáticas

\begin{tabular}{c|c|c|c|c|c}
\hline \multirow{2}{*}{ GhC } & \multicolumn{5}{|c}{ GhF } \\
\cline { 2 - 6 } & $>\mathbf{6 5}$ & $\mathbf{4 5 - 6 5}$ & $\mathbf{2 5 - 4 5}$ & $\mathbf{5 - 2 5}$ & $\leq \mathbf{5}$ \\
\hline$\leq 5$ & ZB1 & ZB2 & ZB3 & ZB4 & ZB5 \\
$5-25$ & ZB6 & ZB7 & ZB8 & ZB9 & ZB10 \\
$25-45$ & --- & --- & ZB11 & ZB12 & ZB13 \\
$45-65$ & --- & --- & --- & ZB14 & ZB15 \\
$>5$ & --- & --- & --- & --- & ZB16 \\
\hline
\end{tabular}

Fonte: Roriz (2012b).

\section{Quadro 4 - Terminologias usadas na Proposta 3}

\begin{tabular}{|l|l|}
\hline \multicolumn{1}{|c|}{ Variável climática } & \multicolumn{1}{c|}{ Cálculo } \\
\hline Tmax: média mensal das temperaturas máximas diárias & \multicolumn{1}{c|}{} \\
\hline Tmin: média mensal das temperaturas mínimas diárias & \\
\hline Tmed: média mensal das temperaturas médias diárias & Tmed $=[$ Tmax+Tmin $] / 2$ \\
\hline TMA: temperatura média anual & $\mathrm{TMA}=\left[\sum_{n=1}^{12} \operatorname{Tmed}(n)\right] / 12$ \\
\hline Amp: amplitude média mensal & $\mathrm{Amp}=\mathrm{Tmax}-\mathrm{Tmin}$ \\
\hline AMA: amplitude média anual & $\mathrm{AMA}=\left[\sum_{n=1}^{12} A m p(n)\right] / 12$ \\
\hline dpT = desvio padrão de Tmed & $\mathrm{dpT}=\left\{\left[\sum_{n=1}^{12} T\left(\operatorname{Tmed}_{(\mathrm{n})}-\mathrm{TMA}\right)^{2}\right] / 11\right\}^{0.5}$ \\
\hline dpA = desvio padrão de Amp & $\mathrm{dpA}=\left\{\left[\sum_{n=1}^{12} T\left(\mathrm{Amp}_{(\mathrm{n})}-\mathrm{AMA}\right)^{2}\right] / 11\right\}^{0.5}$ \\
\hline
\end{tabular}

Fonte: adaptado de Roriz (2013). 
Tabela 5 - Critérios para classificação dos climas pela Proposta 3

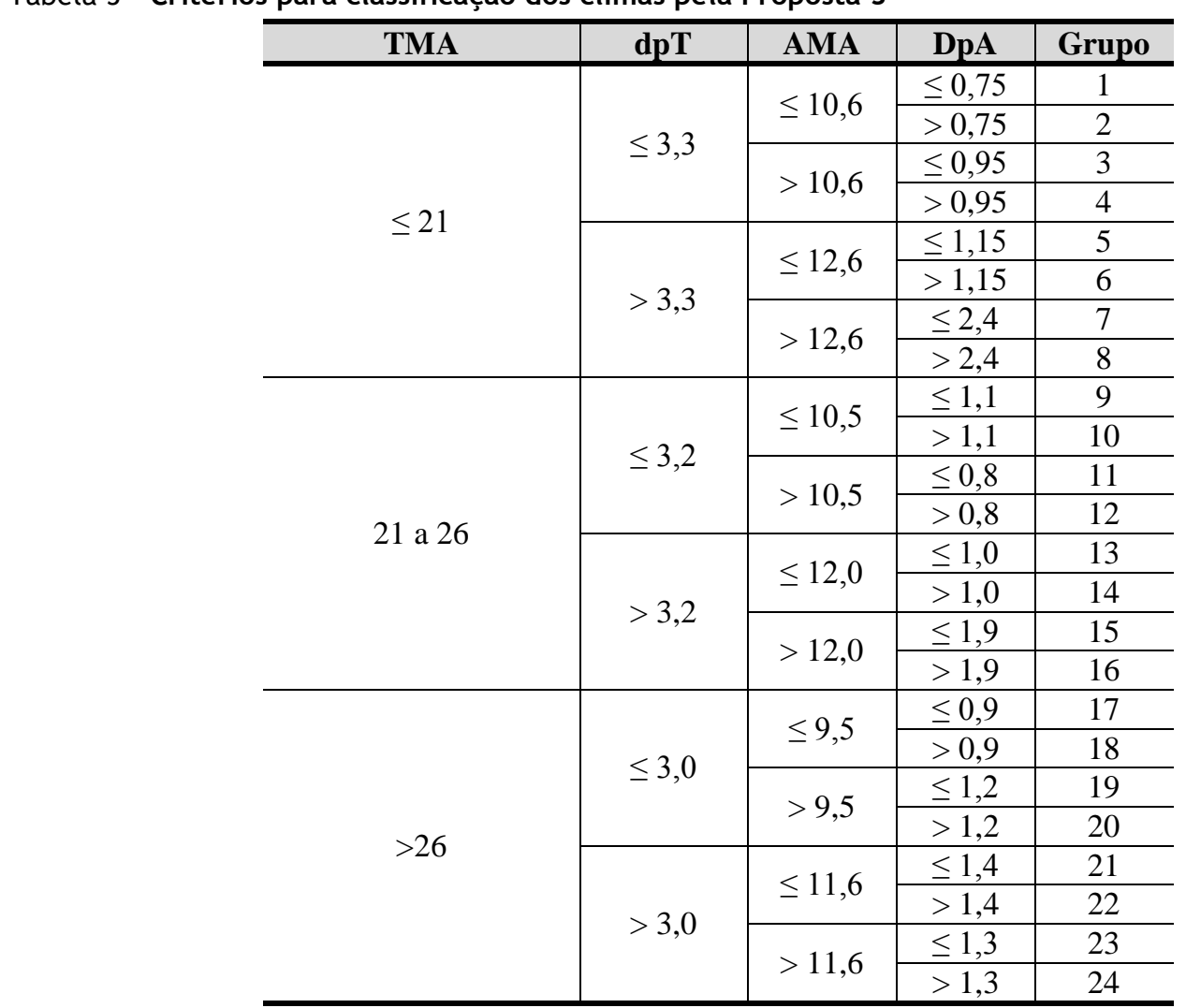

Fonte: adaptado de Roriz (2013).

\section{Proposta 4}

Seguindo a mesma lógica de cálculos e acatando a sugestão de vários pesquisadores, a Proposta 3 recebeu uma atualização, pela qual os intervalos de TMA aumentaram para quatro, fazendo com que o número de zonas bioclimáticas aumentasse para 32. Porém, essa versão foi logo modificada para a Proposta 4. Além disso, esta nova versão retorna à classificação do clima com três intervalos de TMA, conforme a Tabela 6.

Vale ressaltar que entre as Propostas 3 e 4, apesar de se manterem apenas três intervalos de abrangência para a TMA, na Proposta 3 a segunda faixa incluía TMA com valores de $21^{\circ} \mathrm{C}$ a $26^{\circ} \mathrm{C}$, e na Proposta 4, a TMA com abrangência de $21{ }^{\circ} \mathrm{C}$ a $25{ }^{\circ} \mathrm{C}$ (Tabela 6). Essa pequena alteração influencia diretamente nas classificações dos municípios, conforme se verifica nos resultados.

\section{Resultados}

\section{Análise pela NBR 15220-3}

As médias das temperaturas médias mensais, a média das máximas, a média das mínimas, a média da umidade relativa do ar e a média de pressão dos arquivos climáticos TRY e TMY2 foram utilizadas para a confecção da carta bioclimática de Colatina, o que possibilita a análise, pelo programa AnalysisBio, da inserção da região no atual zoneamento bioclimático brasileiro. A Figura 4 mostra a carta bioclimática de Colatina pelo arquivo TMY2.

Em seguida, a figura obtida foi adaptada à carta bioclimática presente em Roriz, Ghisi e Lamberts (1999), conforme a Figura 5.

Em seguida, a figura obtida foi adaptada à carta bioclimática presente em Roriz, Ghisi e Lamberts (1999), conforme a Figura 5.

Considerando os resultados obtidos com a inserção das normais climatológicas no AnalysisBio e, posteriormente, sua inserção na carta bioclimática adaptada de Givoni, obtiveram-se as principais estratégias apresentadas para Colatina com as respectivas percentagens das horas correspondentes a cada estratégia. Para se determinar esse percentual, calculou-se o comprimento total de cada uma das 12 linhas (referentes aos 12 meses do ano) e o comprimento que cada linha ocupava em cada uma das zonas. Seguindo a metodologia de Roriz, Ghisi e Lamberts (1999), os valores menores que $1 \%$ foram desprezados. Em seguida, foram 
selecionadas as três principais estratégias, exceto a da região "E", que é relativa a conforto.

Encontraram-se assim os seguintes resultados:
(a) $\mathrm{F}-16,25 \%$;
(b) $\mathrm{J}-9,87 \%$;
(c) $\mathrm{I}-3,28 \%$.

Para o estado do Espírito Santo, a Norma 152203:2005 classifica somente as cidades listadas a seguir, com suas respectivas estratégias:
(a) Conceição da Barra - FIJ;
(b) São Mateus - FIJ;
(c) Linhares - FIJ; Vitória - FIJ; e
(d) Cachoeiro de Itapemirim - FIJK.

Tabela 6 - Critérios para classificação dos climas pela Proposta 4

\begin{tabular}{|c|c|c|c|c|}
\hline TMA & dpT & AMA & DpA & Grupo \\
\hline \multirow{8}{*}{$\leq 21$} & \multirow{4}{*}{$\leq 3,0$} & \multirow{2}{*}{$\leq 11,1$} & $\leq 1,0$ & 1 \\
\hline & & & $>1,0$ & 2 \\
\hline & & \multirow{2}{*}{$>11,1$} & $\leq 1,6$ & 3 \\
\hline & & & $>1,6$ & 4 \\
\hline & \multirow{4}{*}{$>3,0$} & \multirow{2}{*}{$\leq 10,2$} & $\leq 0,7$ & 5 \\
\hline & & & $>0,7$ & 6 \\
\hline & & \multirow{2}{*}{$>10,2$} & $\leq 0,9$ & 7 \\
\hline & & & $>0,9$ & 8 \\
\hline \multirow{8}{*}{$>21,0 / \leq 25,0$} & \multirow{4}{*}{$\leq 2,1$} & \multirow{2}{*}{$\leq 10,6$} & $\leq 1,0$ & 9 \\
\hline & & & $>1,0$ & 10 \\
\hline & & \multirow{2}{*}{$>10,6$} & $\leq 1,4$ & 11 \\
\hline & & & $>1,4$ & 12 \\
\hline & \multirow{4}{*}{$>2,1$} & \multirow{2}{*}{$\leq 11,9$} & $\leq 1,1$ & 13 \\
\hline & & & $>1,1$ & 14 \\
\hline & & \multirow{2}{*}{$>11,9$} & $\leq 2,1$ & 15 \\
\hline & & & $>2,1$ & 16 \\
\hline \multirow{8}{*}{$>25,0$} & \multirow{4}{*}{$\leq 1,1$} & \multirow{2}{*}{$\leq 9,6$} & $\leq 1,0$ & 17 \\
\hline & & & $>1,0$ & 18 \\
\hline & & \multirow{2}{*}{$>9,6$} & $\leq 1,8$ & 19 \\
\hline & & & $>1,8$ & 20 \\
\hline & \multirow{4}{*}{$>1,1$} & \multirow{2}{*}{$\leq 10,7$} & $\leq 1,2$ & 21 \\
\hline & & & $>1,2$ & 22 \\
\hline & & \multirow{2}{*}{$>10,7$} & $\leq 1,6$ & 23 \\
\hline & & & $>1,6$ & 24 \\
\hline
\end{tabular}

Fonte: adaptada de Roriz (2014).

Figura 4 - Carta bioclimática para Colatina com base nas normais climatológicas do arquivo TMY2

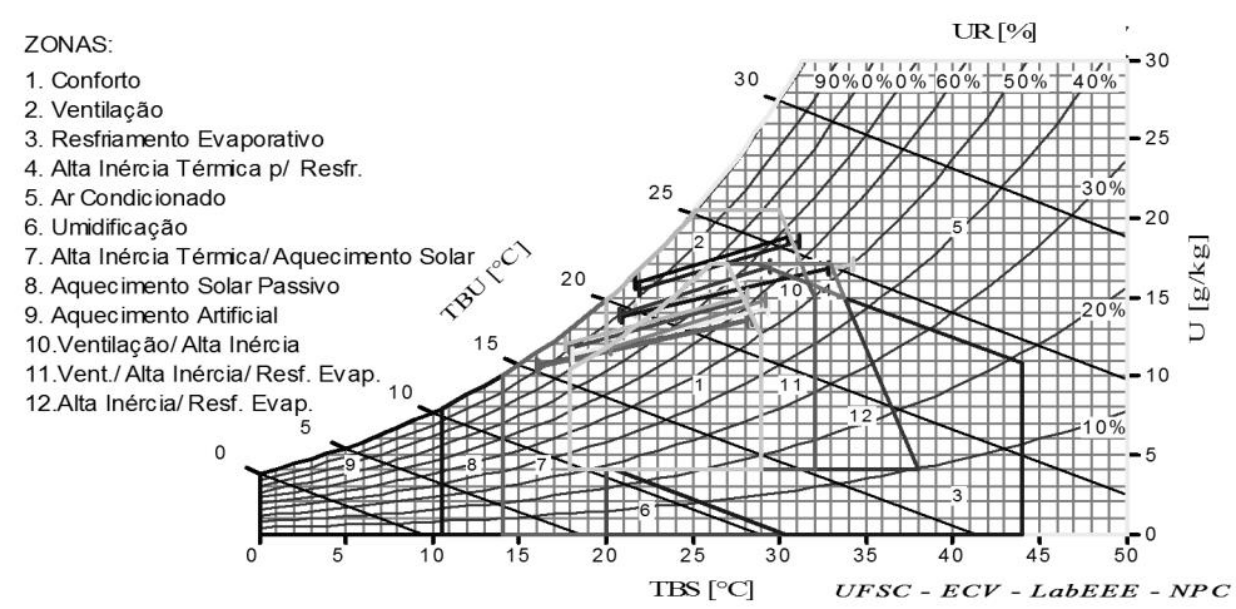

Fonte: AnalysisBio. 
Figura 5 - Carta bioclimática de Colatina com arquivo TMY2 adaptada da carta de Givoni

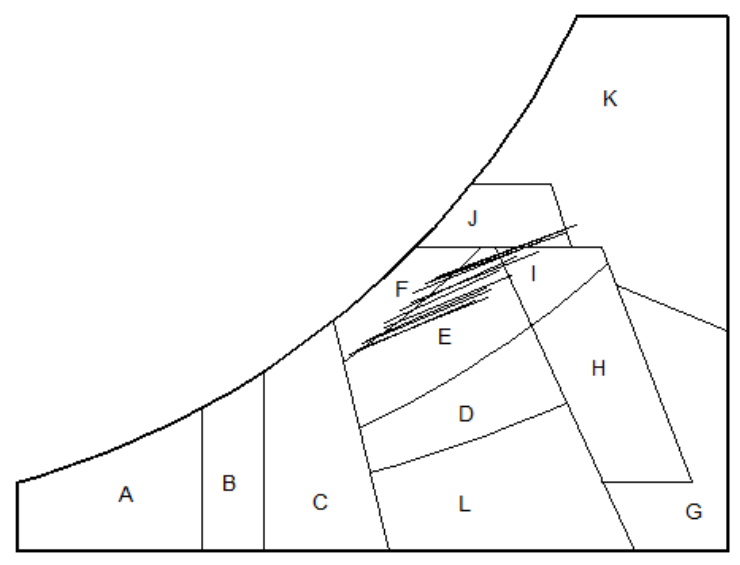

Como Colatina não foi avaliada na NBR 15220 (ABNT, 2005), a inserção das normais climatológicas do arquivo climático local, usandose o atual método de classificação, definiu as estratégias FIJ para a região estudada. Concluiu-se, por analogia, que Colatina segue as estratégias determinadas para os demais municípios do Estado citados na NBR 15220-3 (ABNT, 2005), o que confirma que o município está inserido na ZB8 pelos métodos do atual zoneamento bioclimático sua classificação, anteriormente, era por métodos de interpolação. $\mathrm{O}$ arquivo TRY apresentou valores bem próximos ao TMY2, o que reforça as mesmas estratégias e, consequentemente, a atual classificação bioclimática para Colatina.

\section{Análise pelas propostas de revisão do zoneamento bioclimático brasileiro}

Utilizando-se como base os dados dos arquivos climáticos TRY E TMY2 definidos para Colatina, procedeu-se à análise por cada método de revisão proposto para se verificar a inserção do município de Colatina nas propostas de revisão. Pelo método da Proposta 1, que estabelece 20 zonas, os dados dos arquivos climáticos de Colatina indicaram sua inserção na ZB16, conforme a Tabela 7.

Observa-se que o método de confecção do arquivo climático não influenciou a classificação. Em ambas as situações, Colatina estaria inserida na mesma zona bioclimática. Por esta proposta de zoneamento bioclimático, Colatina seria inserida em uma zona bioclimática diferente de Vitória, o que hoje não ocorre. A Tabela 8 apresenta a classificação dos municípios mais próximos de
Colatina que possuem estações do Inmet (Linhares, ES, e Aimorés, MG), a capital do estado (Vitória), além de Colatina.

A região de Colatina não faria parte de nenhuma das zonas bioclimáticas estabelecidas para os municípios vizinhos, por pertencer à zona bioclimática 16. O resultado também contradiz o que está colocado nesta proposta de revisão, que classifica Colatina na ZB10, segundo a "Classificação Bioclimática das Sedes dos Municípios Brasileiros", disponível no site do LabEEE. Nessa classificação, os dados de Colatina foram obtidos por equações de regressão, enquanto a classificação na ZB16 deu-se através dos dados climáticos obtidos na estação meteorológica local.

Na Proposta 2 novamente o cálculo foi feito com os dois arquivos climáticos (TRY e TMY2) para se verificar a inserção de Colatina no zoneamento proposto e se haveria alteração entre um método ou outro de criação do arquivo climático. A Tabela 7 apresenta os resultados encontrados. Como nesta proposta de revisão do zoneamento bioclimático não consta uma tabela de classificação dos municípios, como ocorreu na Proposta 1, foi necessário se calcularem os intervalos de GhC e GhF para as cidades próximas de Colatina, que seriam Linhares e Aimorés, e também para a capital, Vitória, como demonstrado na Tabela 9.

Por essa proposta contata-se que Linhares e Vitória fariam parte de uma mesma zona, ao contrário do ocorre na proposta anterior, e Colatina insere-se na mesma zona bioclimática de Aimorés, MG. Vale lembrar que o método desta proposta trabalha com um número menor de zonas bioclimáticas, quatro a menos do que o método anterior. 
Tabela 7 - Resultados da Proposta 1 para Colatina com base nos arquivos climáticos TMY2 e TRY

\begin{tabular}{l|c|c}
\hline \multirow{2}{*}{ Dados } & \multicolumn{2}{|c}{ Arquivo climático } \\
\cline { 2 - 3 } & Colatina TMY2 & Colatina TRY \\
\hline TmedAno & 24,88 & 24,94 \\
dT & 5,85 & 6,80 \\
Amed Ano & 10,61 & 11,08 \\
dA & 3,93 & 4,26 \\
Classificação & Z16 & Z16 \\
\hline
\end{tabular}

Tabela 8 - Zonas bioclimáticas de algumas cidades próximas de Colatina segundo a Proposta 1

\begin{tabular}{l|c}
\hline \multicolumn{1}{c|}{ Cidade } & Zona Bioclimática \\
\hline Colatina TMY2 & 16 \\
Colatina TRY & 16 \\
Linhares & 09 \\
Vitória & 10 \\
Aimorés & 13 \\
\hline
\end{tabular}

Tabela 9 - Graus-hora de frio e calor e respectiva zona bioclimática segundo a Proposta 2

\begin{tabular}{l|c|c|c}
\hline Arquivo climático & GhF & GhC & Zona bioclimática \\
\hline Colatina TMY2 & 34,3 & 26,20 & 13 \\
Colatina TRY & 33,8 & 31,07 & 13 \\
Linhares & 33,8 & 17,96 & 10 \\
Vitória & 35,4 & 26,20 & 10 \\
Aimorés & 33,6 & 26,72 & 13 \\
\hline
\end{tabular}

Os métodos descritos nas Propostas 3 e 4 aumentam o número de zonas bioclimáticas para 24. Além disso, destaca-se que a base de dados do Incaper passou a ser usada como fonte de dados climáticos e que, portanto, o município de Marilândia, ES (sede da estação meteorológica que forneceu dados para a criação dos arquivos climáticos de Colatina ${ }^{2}$ ) foi incluído nas classificações, porém com dados climáticos distintos aos dos arquivos climáticos de Colatina usados para a confecção de TMY2 e TRY. Para a confecção dos arquivos TMY2 e TRY de Colatina foram utilizados dados de quatro anos de medições provenientes de estação automática, enquanto para a classificação de Marilândia, realizada por Roriz (2013), foram usados dados de temperatura da estação convencional em funcionamento desde os anos 1970, além dos dados da estação automática. Assim, pela Proposta 3 os cálculos indicaram que a cidade de Colatina se insere em uma zona bioclimática diferente da de Marilândia. No entanto, houve proximidade na classificação das zonas bioclimáticas, ficando Colatina na zona 12 e Marilândia na zona bioclimática 13 (Tabela 10).

Apesar da pequena diferença na classificação de Colatina para Marilândia, destaca-se que, embora existam limitações, essa é uma realidade que tende

${ }^{2}$ Marilândia era distrito de Colatina até o início dos anos 1980, quando se tornou município. a crescer no país, com a implantação de mais estações automáticas no Brasil. Mesmo com o fato de Roriz (2013) trabalhar com dados de temperatura da estação manual e, por consequência, com períodos maiores de registros, há tendência de se trabalhar com arquivos provenientes de estações automáticas. Roriz (2012c) relata que normalmente os dados obtidos em períodos mais longos tendem a ser mais consistentes. Porém, ressalta que essas fontes englobam apenas médias mensais e não atendem aos requisitos exigidos pelos principais programas computacionais para simulação termoenergética, que permitirão definições posteriores quanto a zoneamentos bioclimáticos específicos para as diferentes tipologias construtivas. Ressalta ainda o alerta que já constava no texto de apresentação de dados EPW-Antac, "[...] para grande parte dos municípios constantes da base do Inmet foi possível montar-se poucos anos inteiros, com dados a partir de 2007/2008 [...]" (RORIZ, 2012c, p. 1). Dessa forma, os arquivos apresentam baixa representatividade estatística das ocorrências climáticas históricas, porém deverão ser aperfeiçoados com dados de períodos mais longos de registros para compor essa base de dados para simulações.

A Proposta 4, que altera a faixa de abrangência dos dados, tanto de TMA, AMA, dpT e dpA, 
apresentou um fato que até então não havia ocorrido nas outras propostas de revisão. Pela primeira vez o método classificação foi sensível ao tipo de arquivo climático usado. Enquanto o arquivo TMY2 insere Colatina na zona bioclimática 10, o arquivo TRY insere Colatina na zona bioclimática 11. A Tabela 11 apresenta a situação de Colatina e demais municípios pelo método da Proposta 4.

Essa diferença de classificação da zona bioclimática para Colatina, ocorrida em face dos arquivos criados por metodologias diferentes (TRY e TMY2), ocorre porque a amplitude média anual influenciou diretamente a classificação nesta proposta de revisão em relação às demais, apesar de a variação entre o arquivo TMY2 e TRY ser bem pequena. Comparado-se com a Proposta 3, uma pequena mudança de casa decimal já altera os parâmetros de sensibilidade da classificação. Se a Proposta 4 estabelecesse na abrangência da amplitude média anual as mesmas faixas de abrangência da Proposta 3 (valores $\leq 10,5$ ou $>$ 10,5), essa diferenciação não teria ocorrido. Guimarães, Amorim e Carlo (2014) já haviam indicado que o uso de diferentes métodos para criar arquivos climáticos poderia apresentar diferenças em simulações devido a outros fatores (radiação, direção e velocidade dos ventos) que compõem um arquivo climático, mas sem alterações expressivas com relação a dados de temperaturas. Porém, embora as temperaturas tendam a ser mais semelhantes que os demais parâmetros, as amplitudes do TRY e do TMY2, de $11,1{ }^{\circ} \mathrm{C}$ e $10,6{ }^{\circ} \mathrm{C}$ respectivamente, foram suficientes para resultar em classificações diferentes de zoneamento. Isso evidencia a elevada sensibilidade da Proposta 4, que pode levar a discrepâncias na classificação em razão do tipo de arquivo adotado. Essa proposta poderia ser evitada, visto que o zoneamento bioclimático não deve ser impactado por formatos distintos de arquivos climáticos quando estes têm a mesma base de dados.

Silva, Almeida e Ghisi (2013), ao analisar dados de arquivos TRY e TMY da cidade de Florianópolis, também detectaram diferenças entre temperaturas de bulbo seco e umidade relativa entre os arquivos, e citaram que, mesmo que as diferenças de temperatura pareçam pequenas, a umidade relativa pode apontar para diferentes resultados. De fato, Pernigotto et al. (2014) afirmam que, quando se tem um baixo número de anos no conjunto de dados para o desenvolvimento dos arquivos TRY, a representatividade das variáveis meteorológicas ou as necessidades de energia podem variar significativamente em diferentes localizações. Aliado a isso, alterações microclimáticas próximas à estação que registra os dados podem também influenciar os resultados na composição dos arquivos climáticos quando se utilizam anos diferentes.

Como os dados para a confecção dos arquivos climáticos TMY2 e TRY vieram da mesma estação meteorológica, a precisão do equipamento de medição pouco interferiu nessa classificação. Uma vez que os dados dos arquivos climáticos TMY2 ou TRY foram selecionados pelos extremos de médias de temperaturas, eliminados para uma série temporal, a precisão do equipamento não foi a maior incerteza que se refletiu na qualidade dos dados. Guimarães e Carlo (2015), ao comparar os arquivos TRY, TMY e TMY3, concluíram em suas análises que os resultados, independentemente do método de criação do arquivo climático adotado, tendem a ser semelhantes desde que sejam usados dados de uma mesma fonte de coleta. Porém, ressaltam que, mesmo com diferenças discretas dos dados climáticos, nas simulações ocorreram variações significativas nos resultados, chegando a até $14 \%$.

Tabela 10 - Classificação dos climas segundo a Proposta 3 da revisão do zoneamento bioclimático brasileiro

\begin{tabular}{l|c|c|c|c|c}
\hline \multicolumn{1}{c|}{ Arquivo Climático } & TMA & dpT & AMA & dpA & Grupo \\
\hline Colatina TMY2 & 24,9 & 2,1 & 10,6 & 1,5 & 12 \\
Colatina TRY & 24,9 & 2,1 & 11,1 & 1,3 & 12 \\
Marilândia & 24,7 & 3,3 & 11,6 & 0,6 & 13 \\
Linhares & 24,4 & 2,6 & 9,1 & 0,7 & 09 \\
Vitória & 25,1 & 2,0 & 7,1 & 0,4 & 09 \\
Aimorés & 26,0 & 3,5 & 12,0 & 1,1 & 23 \\
\hline
\end{tabular}

Nota: Legenda:

TMA: temperatura média anual;

Amp: amplitude média mensal;

AMA: amplitude média anual;

dpT: desvio padrão de Tmed; e

dpA: desvio padrão de Amp. 
Tabela 11 - Classificação dos climas segundo a Proposta 4 da revisão do zoneamento bioclimático brasileiro

\begin{tabular}{l|c|c|c|c|c}
\hline Arquivo climático & TMA & dp T & AMA & dpA & Grupo \\
\hline Colatina TMY2 & 24,9 & 2,1 & 10,6 & 1,5 & 10 \\
Colatina TRY & 24,9 & 2,1 & 11,1 & 1,3 & 11 \\
Marilândia & 24,7 & 3,3 & 11,6 & 0,6 & 13 \\
Linhares & 24,4 & 2,6 & 9,1 & 0,7 & 13 \\
Vitória & 25,1 & 2,0 & 7,1 & 0,4 & 21 \\
Aimorés & 26,0 & 3,5 & 12,0 & 1,1 & 23 \\
\hline
\end{tabular}

Nota: Legenda:

TMA: temperatura média anual;

Amp: amplitude média mensal;

AMA: amplitude média anual;

dpT: desvio padrão de Tmed; e

dpA: desvio padrão de Amp.

A Tabela 12 apresenta um comparativo geral, que representa a classificação bioclimática do município de Colatina e demais municípios analisados, onde se constata que o aumento de zonas bioclimáticas em cada proposta de revisão classifica Colatina em zonas diferenciadas às demais localidades no Espírito Santo, ao contrário do que ocorre atualmente pela NBR 15220-3 (ABNT, 2005), pela qual toda a região enquadra-se numa única zona bioclimática. Também mostra a sensibilidade da Proposta 4, em que a classificação bioclimática de Colatina pode apresentar resultados diferentes em função do método de criação do arquivo climático.

Roriz (2014) afirma que o objetivo atual da revisão se limita a estabelecer um mapeamento dos climas no Brasil, porém prevê que em etapas posteriores, através de simulações computacionais, poderão ser definidos zoneamentos bioclimáticos que sejam específicos para diferentes tipologias construtivas, como habitação, comércio ou indústria, e dessa forma possam ser identificadas estratégias construtivas a ser recomendadas para cada uma dessas tipologias. Se hoje arquivos climáticos são desenvolvidos em função da sensibilidade da edificação a seus parâmetros climáticos, um novo zoneamento bioclimático pode se voltar à análise dessa sensibilidade, bem como se diferenciar pelas tipologias de edificações, comercial, institucional ou residencial. Essas novas tendências de tratamento bioclimático podem ser incorporadas em novas propostas ainda mais abrangentes.

\section{Conclusões}

O zoneamento bioclimático brasileiro é hoje uma realidade, independentemente dos questionamentos sobre suas adequações. O processo de revisão em discussão até 2016 evidencia a percepção de algumas discrepâncias encontradas em várias localidades do país, observadas em vários estudos e pesquisas feitos desde a publicação da NBR 15220-3 (ABNT, 2005). Os resultados obtidos nesta pesquisa mostram a importância de se estabelecer quais metodologias deverão ser usadas para se definirem as zonas bioclimáticas. A comparação do zoneamento atual, que classifica a cidade de Colatina e várias outras cidades do estado do Espírito Santo em uma única zona bioclimática, no caso a ZB8, com as metodologias de revisão, já mostra que os municípios da região norte/noroeste do Espírito Santo podem apresentar climas diferenciados entre si e diferentes ao da capital, Vitória. Enquanto na metodologia da primeira revisão Colatina e Aimorés, MG, estariam em uma mesma zona bioclimática, nas demais propostas isso não ocorre, assim como Linhares e Colatina estão hoje na mesma zona bioclimática e passam a estar inseridas em zonas diferenciadas pelas metodologias de revisão.

Propostas muito abrangentes territorialmente, como a do atual zoneamento, tendem a não representar bem a classificação climática de locais tão distintos em relação ao relevo ou disponibilidade de ventos, e assim tendem a mascarar diferenças climáticas significativas para o desempenho das edificações e conforto de seus usuários. Por outro lado, critérios que sejam rigorosos demais, com delimitação de várias faixas para a classificação de zonas bioclimáticas, podem resultar em uma excessiva quantidade de zonas e, dessa forma, gerar equívoco nas classificações, tal como a separação do TRY e TMY2 de Colatina em duas zonas distintas. 
Tabela 12 - Comparativo geral com a classificação bioclimática do município de Colatina e demais municípios analisados

\begin{tabular}{c|c|c|c|c|c|c}
\hline UF & Município & $\begin{array}{c}\text { Zona } \\
\text { bioclimática } \\
\text { pela NBR } \\
\mathbf{1 5 2 2 0 - 3}\end{array}$ & $\begin{array}{c}\text { Zona } \\
\text { bioclimática } \\
\text { pela } \\
\text { Proposta 1 }\end{array}$ & $\begin{array}{c}\text { Zona } \\
\text { bioclimática } \\
\text { pela } \\
\text { Proposta 2 }\end{array}$ & $\begin{array}{c}\text { Zona } \\
\text { bioclimática } \\
\text { pela } \\
\text { Proposta 3 }\end{array}$ & $\begin{array}{c}\text { Zona } \\
\text { bioclimática } \\
\text { pela Proposta } \\
\mathbf{4}\end{array}$ \\
\hline ES & $\begin{array}{c}\text { Colatina }- \\
\text { TMY2 }\end{array}$ & 8 & 16 & 13 & 12 & 10 \\
\hline ES & $\begin{array}{c}\text { Colatina }- \\
\text { TRY }\end{array}$ & 8 & 16 & 13 & 12 & 11 \\
\hline ES & Marilândia & 8 & $\begin{array}{c}\text { Não } \\
\text { classificada }\end{array}$ & $\begin{array}{c}\text { Não } \\
\text { classificada }\end{array}$ & 13 & 13 \\
\hline ES & Linhares & 8 & 09 & 10 & 09 & 13 \\
\hline ES & Vitoria & 8 & 10 & 10 & 09 & 21 \\
\hline MG & Aimorés & 5 & 13 & 13 & 23 & 23 \\
\hline
\end{tabular}

Outro fator a ser considerado é a sensibilidade do método da Proposta 4, que coloca a possibilidade de um mesmo município, Colatina, ser inserido em duas zonas climáticas distintas em função do arquivo climático escolhido. Uma pequena mudança de valores nas casas decimais na amplitude média anual e de desvio padrão de amplitude já seria suficiente para os arquivos climáticos de Colatina serem inseridos numa mesma zona bioclimática. Essa sensibilidade pode influenciar diretamente nas classificações dos municípios em função do método de confecção de arquivos escolhido. A própria mudança de classificação que ocorre com a cidade de Vitória quando se analisam as Propostas 3 e 4 demonstra esse cuidado.

$\mathrm{O}$ esforço da equipe de pesquisadores em obter maior número de dados locais através de medições e, desta forma, diminuir o número de localidades com definições climáticas através de métodos de interpolação possibilita que os estudos de climas colaborem para a definição de estratégias bioclimáticas adequadas para cada localidade. As definições climáticas do local podem interferir diretamente nas recomendações e estratégias de condicionamento térmico das edificações. Esta pesquisa mostra que, apesar de se terem várias opções de metodologias para a definição de zonas bioclimáticas, ainda não há uma definição de qual é a mais adequada, o que indica a necessidade de estudos para aprofundar essas questões. A sinalização por parte da equipe responsável pela revisão do zoneamento, em se utilizarem mais arquivos climáticos em formato epw para a definição das zonas bioclimáticas, possibilita a utilização de simulações para a avaliação de desempenho de materiais e características construtivas e, desta forma, auxilia na definição sobre qual método pode ser o mais adequado para a classificação climática.

\section{Referências}

ASSOCIAÇÃO BRASILEIRA DE NORMAS TÉCNICAS. ABNT. NBR 15220-3: desempenho térmico de edificações: parte 3: zoneamento bioclimático brasileiro e diretrizes construtivas para habitações unifamiliares de interesse social. Rio de Janeiro, 2005.

BARNABY, C. S.; CRAWLEY, D. B. Weather Data for Building Performance Simulation.

Building Perfomance Simulation for Design and Operation, p. 37-55, 2011.

BOGO, A. J. Limitações Quanto aos Parâmetros de Desempenho Térmico e Estratégias Bioclimáticas Recomendadas pela Norma Brasileira de Desempenho Térmico de Habitações de Interesse Social. São Paulo: Núcleo de pesquisa em tecnologia da arquitetura e urbanismo da Universidade de São Paulo, 2008.

CARVALHO, H. J. M.; ARAÚJO, T. G. H.; SILVA, F. A. G. Tratamento de Dados Climáticos da Cidade de João Pessoa - PB, Para o Uso em Projetos de Arquitetura. In: ENCONTRO

NACIONAL DE TECNOLOGIA DO AMBIENTE CONSTRUÍDO, 9., Foz do Iguaçu, 2002. Anais... Foz do Iguaçu: ANTAC, 2002.

FERREIRA, C.; SOUZA, H. A.; ASSIS, E. S. Estudo do Clima Brasileiro: reflexões e recomendações sobre a adequação climática de habitações. In: ENCONTRO NACIONAL DE TECNOLOGIA DO AMBIENTE CONSTRUÍDO, 15., Maceió, 2014. Anais... Maceió: ANTAC, 2014. 
GUIMARÃES, Í. B. B.; CARLO, J. C.

Comparação Estatística Entre Arquivos Climáticos Desenvolvidos Com Método Diferentes. In: LATIN-AMERICAN AND EUROPEAN CONFERENCE ON SUSTAINABLE BUILDINGS AND COMMUNITIES, Guimarães, 2015. Proceedings... Guimarães: EURO-ELECS, 2015.

GUIMARÃES. Í. B. B.; AMORIM, A. C., CARLO, J. C. Comparação Estatística e Por Simulação de Arquivos Climáticos TRY e TMT, Desenvolvidos Para a Cidade de Viçosa - MG. In: CONFERÊNCIA INTERNACIONAL REGSA 2014. ENERGIAS RENOVÁVEIS, EFICIÊNCIA ENERGÉTICA E DESENVOLVIMENTO, Florianópolis, 2014. Anais... Florianópolis: Unisul, 2014.

GOOGLE. Google Earth. Version 7. 2015. Disponível em: <https://www.google.com.br/intl/pt-BR/earth/>. Acesso em: 16 mar. 2015.

INSTITUTO BRASILEIRO DE GEOGRAFIA E ESTATISTICA. Indicadores Sociais Municipais. Disponível em:

<http://www.ibge.gov.br/home/estatistica/populaca o/indicadores_sociais_municipais/tabela1 a.shtm>. Acesso em: 29 maio 2013.

INTERNATIONAL CODE COUNCIL. International Energy Conservation Code. 2012.

MARTINS, T. A. L.; BITTENCOURT, L. S.; KRAUSE, C. M. de L. B. Contribuição ao Zoneamento Bioclimático Brasileiro: reflexões sobre o semiárido nordestino. Ambiente Construído, Porto Alegre, v. 12, n. 2, p. 59-75, abr./jun. 2012.

MARTINS, T. A. L.; BITTENCOURT, L.; KRAUSE, C. B. Contribuição ao Zoneamento Bioclimático Brasileiro: Reflexões sobre o semiárido nordestino. In: ENCONTRO NACIONAL DE CONFORTO NO AMBIENTE CONSTRUÍDO, 11., Búzios, 2011. Anais... Búzios: ANTAC, 2011.

NIMER, E. Um Modelo Metodológico de Classificação de Climas. Revista Brasileira de Geografia, Rio de Janeiro, v. 41, p. 59-89, out./dez. 1979.

PEREIRA, I; ASSIS, E. S. D. Discussão da Classificação Bioclimática de Belo Horizonte Proposta Pelo Projeto de Norma de Desempenho das Edificações. In: ENCONTRO NACIONAL DE TECNOLOGIA DO AMBIENTE CONSTRUIIDO, 8., Maceió, 2004. Anais... Maceió: ENTAC, 2004.
PERNIGOTTO, G. et al. Multi-Year and Reference Year Weather Data for Building Energy Labelling in North Italy Climates. Energy and Buildings, v. 72, p.62-72, abr. 2014.

PEZZOPANE, J. E. M. et al. Agrometeorologia: aplicações para o Espírito Santo. Alegre: Caufes, 2012.

PORTUGAL. Decreto-Lei $\mathbf{n}^{\mathbf{0}} 80$, de 4 de abril de 2006, que aprova o Regulamento das

Características de Comportamento Térmico dos Edifícios (RCCTE). Lisboa, 2006. Disponível em: <http://www.rccte.com/>. Acesso em: 15 mar. 2016.

ROCHA, A. P. A.; ASSIS, E. S.; GONÇALVES, W. B. Zoneamento Bioclimático do Estado de Minas Gerais: aperfeiçoamento dos resultados. In: ENCONTRO NACIONAL DE CONFORTO NO AMBIENTE CONSTRUÍDO, 10., Natal, 2009. Anais... Natal: ANTAC, 2009.

RORIZ, M. Um Método Para a Interpolação de Dados Climáticos. In: ENCONTRO NACIONAL DE CONFORTO NO AMBIENTE CONSTRUÍDO, 5., Fortaleza, 1999. Anais... Fortaleza: ANTAC, 1999.

RORIZ, M. Zoneamento Bioclimático do Brasil. São Carlos: UFSCar, 2004. Programa que fornece a classificação bioclimática das sedes dos municípios brasileiros e diretrizes construtivas para habitações unifamiliares de interesse social. Disponível em: <http://www.roriz.eng.br/download_6.html>. Acesso em: 15 fev. 2014.

RORIZ, M. Uma Proposta de Revisão do Zoneamento Bioclimático Brasileiro. 2012a. Disponível em:

<http://www.labeee.ufsc.br/projetos/proposta-derevisao-do-zoneamento-bioclimatico-brasileiro>. Acesso em: 20 maio 2013.

RORIZ, M. Segunda Proposta de Revisão do Zoneamento Bioclimático do Brasil. 2012b. Disponível em: $<$ http://www.labeee.ufsc.br/projetos/proposta-derevisao-do-zoneamento-bioclimatico-brasileiro>. Acesso em: 20 maio 2013.

RORIZ, M. Correções nas Irradiâncias e Iluminâncias dos Arquivos EPW da Base Antac. 2012c. Disponível em: <http://www.labeee.ufsc.br/sites/default/files/arqui vos_climaticos/correcao_epw_antac.pdf > . Acesso em: 12 maio 2015.

390 Amorim, A. C.; Carlo, J. C. 
RORIZ, M. Classificação de Climas do Brasil Versão 2. 2013. Disponível em:

$<$ http://www.labeee.ufsc.br/projetos/proposta-derevisao-do-zoneamento-bioclimatico-brasileiro>. Acesso em: 23 jul. 2014.

RORIZ, M. Classificação de Climas do Brasil Versão 3. 2014. Disponível em:

http://www.labeee.ufsc.br/projetos/proposta-derevisao-do-zoneamento-bioclimatico-brasileiro>. Acesso em: 23 jul. 2014.

RORIZ, M.; GHISI, E.; LAMBERTS R. Uma Proposta de Norma Técnica Brasileira Sobre Desempenho Térmico de Habitações Populares. In: ENCONTRO NACIONAL DE CONFORTO NO AMBIENTE CONSTRUÍDO, 5., Fortaleza, 1999. Anais... Fortaleza: ENCAC-ELECAC, 1999.

SILVA, A. C. S. B. Zoneamento Bioclimático Brasileiro Para Fins de Edificação. Porto Aelgre, 1994. 124 f. Dissertação (Mestrado) -

Departamento de Engenharia, Universidade Federal do Rio Grande do Sul, Porto Alegre, 1994.
SILVA, A. S.; ALMEIDA, L. S. S.; GHISI, E. Comparação da Eficiência Energética da Envoltória de Habitações de Interesse Social Pelos Métodos Prescritivo e Simulação do RTQ-R. In: ENCONTRO NACIONAL DE CONFORTO NO AMBIENTE CONSTRUÍDO, 12., Brasília, 2013. Anais... Brasília: ANTAC, 2013.

TAVARES, L. R.; AMORIM, C. N. D. Elaboração do Arquivo Climático Horário da Cidade de Uberlândia-MG Para Simulação de Desempenho Energético Segundo o RTQ-C. In: ENCONTRO NACIONAL DE CONFORTO NO AMBIENTE CONSTRUÍDO, 11., Búzios, 2011. Anais... Búzios: ANTAC, 2011.

\section{Agradecimentos}

Os autores agradecem ao professor Mauricio Roriz, por toda a atenção dispensada durante a realização da pesquisa, e ao Procel Edifica/Eletrobrás, pelo financiamento da bolsa.

Alexandre Cypreste Amoprin

Coordenadoria de Arquitetura e Urbanismo | Instituto Federal do Espírito Santo | Av. Arino Gomes Leal, 1700, Campus Colatina, Santa Margarida | Colatina - ES - Brasil | CEP 29700-558 | Tel.: (27) 3723-1518 | E-mail: cypreste@ifes.edu.br

Joyce Correna Carlo

Departamento de Arquitetura e Urbanismo | Universidade Federal de Viçosa | Av. P. H. Rofls, s/n, Centro | Viçosa - MG - Brasil | CEP 36570-000 | Tel.: (31) 3899-1982 | E-mail: joycecarlo@ufv.br

Revista Ambiente Construído

Associação Nacional de Tecnologia do Ambiente Construído

Av. Osvaldo Aranha, $99-3^{\circ}$ andar, Centro

Porto Alegre - RS - Brasil CEP $90035-190$

Telefone: +55 (51) 3308-4084

Fax: +55 (51) 3308-4054

www.seer.ufrgs.br/ambienteconstruido

E-mail: ambienteconstruido@ufrgs.br 